\title{
Communication
}

\section{Natural Antimicrobials Suitable for Combating Desiccation-Resistant Salmonella enterica in Milk Powder}

\author{
Ahmed G. Abdelhamid ${ }^{1,2}$ and Ahmed E. Yousef 1,3,* \\ 1 Department of Food Science and Technology, The Ohio State University, 2015 Fyffe Court, \\ Columbus, OH 43210, USA; abdelhamid.9@osu.edu \\ 2 Botany and Microbiology Department, Faculty of Science, Benha University, Benha 13518, Egypt \\ 3 Department of Microbiology, The Ohio State University, 105 Biological Sciences Building, 484 West 12th \\ Avenue, Columbus, $\mathrm{OH} 43210$, USA \\ * Correspondence: yousef.1@osu.edu
}

Citation: Abdelhamid, A.G.; Yousef, A.E. Natural Antimicrobials Suitable for Combating Desiccation-Resistant Salmonella enterica in Milk Powder. Microorganisms 2021, 9, 421. https://doi.org/10.3390/ microorganisms 9020421

Academic Editor: María-Jesús Grilló Received: 17 January 2021

Accepted: 14 February 2021

Published: 18 February 2021

Publisher's Note: MDPI stays neutral with regard to jurisdictional claims in published maps and institutional affiliations.

Copyright: (c) 2021 by the authors. Licensee MDPI, Basel, Switzerland. This article is an open access article distributed under the terms and conditions of the Creative Commons Attribution (CC BY) license (https:// creativecommons.org/licenses/by/ $4.0 /)$.

\begin{abstract}
Some Salmonella enterica strains survive well in low-water activity (low- $\left.\mathrm{a}_{\mathrm{w}}\right)$ foods and cause frequent salmonellosis outbreaks in these products. Methods are needed to overcome such desiccation-resistant Salmonella and to improve the safety of low- $\mathrm{a}_{\mathrm{w}}$ foods. Building on a recent finding, we hypothesized that natural antimicrobial food additives, which are active against cytoplasmic membrane, could overcome this desiccation resistance phenomenon, and thus, sensitize the pathogen to drying and mild processing. Food additives were screened for the ability to cause leakage of intracellular potassium ions; retention of these ions is vital for protecting Salmonella against desiccation. Two antimicrobial food additives, carvacrol and thymol, caused considerable potassium leakage from the desiccation-resistant S. enterica serovars, Tennessee and Livingstone. Thus, carvacrol and thymol were investigated for their ability to sensitize the desiccation-adapted $S$. enterica to heat treatment. The combined use of food additives, at their minimum inhibitory concentrations, with heat treatment at $55^{\circ} \mathrm{C}$ for 15 min caused $3.1 \pm 0.21$ to more than 5.5 log colony forming unit $(\mathrm{CFU}) / \mathrm{mL}$ reduction in desiccation-adapted S. enterica, compared to $2.4 \pm 0.53-3.2 \pm 0.11 \log$ $\mathrm{CFU} / \mathrm{mL}$ reduction by sole heat treatment. Carvacrol was the additive that caused the greatest potassium leakage and sensitization of Salmonella to heat; hence, the application of this compound was investigated in a food model against Salmonella Typhimurium ASD200. Addition of carvacrol at 200 or 500 ppm into liquid milk followed by spray-drying reduced the strain's population by $0.9 \pm 0.02$ and $1.3 \pm 0.1 \log \mathrm{CFU} / \mathrm{g}$, respectively, compared to $0.6 \pm 0.02 \mathrm{log} \mathrm{CFU} / \mathrm{g}$ reduction for non-treated spray-dried milk. Additionally, freeze-drying of milk treated with high levels of carvacrol (5000 ppm) reduced the population of Salmonella Typhimurium ASD200 by more than $4.5 \mathrm{log}$ CFU/g, compared to $1.1 \pm 0.4 \log \mathrm{CFU} / \mathrm{g}$ reduction for the freeze-dried untreated milk. These findings suggest that carvacrol can combat desiccation-resistant $S$. enterica, and thus, potentially improve the safety of low- $\mathrm{a}_{\mathrm{w}}$ foods.
\end{abstract}

Keywords: natural antimicrobials; food additives; Salmonella enterica; desiccation resistance; low$\mathrm{a}_{\mathrm{w}}$ foods

\section{Introduction}

Low-water activity (low- $\mathrm{a}_{\mathrm{w}}$ ) foods are shelf-stable products with an $\mathrm{a}_{\mathrm{w}}$ of less than 0.85; these include nuts and nut products, honey, spices, dried fruits, and others [1]. In the past two decades, there has been a noticeable increase in the incidence of disease outbreaks linked to low- $\mathrm{a}_{\mathrm{w}}$ foods such as cereals, nut butter and crackers [2-4]. It is estimated that $45 \%$ of these outbreaks and the majority of hospitalizations (89\%) and deaths (74\%), linked to low $-\mathrm{a}_{\mathrm{w}}$ foods are caused by various Salmonella enterica serovars [5]. S. enterica may adapt to the dry conditions in these foods and become desiccation-resistant. This adaptation not only allows pathogen cells to survive for long periods in low- $\mathrm{a}_{\mathrm{w}}$ foods, but also cross-protects these cells against lethal steps in product processing [6]. 
Despite the progress in assessing the risk of salmonellosis associated with low- $\mathrm{a}_{\mathrm{w}}$ foods, limited literature addressed strategies to disrupt the desiccation resistance once it is acquired by S. enterica. Researchers have proposed increasing process lethality (e.g., elevating heat-treatments) to overcome Salmonella in low- $\mathrm{a}_{\mathrm{w}}$ foods [7]. However, the severity of these treatments is likely to damage the quality of the final product. Hence, our goal was to explore methods to overcome desiccation-resistant Salmonella without excessive processing. In a previous study, we found that a newly discovered microbial lipopeptide, paenibacterin, disrupted the desiccation resistance in S. enterica and rendered the pathogen sensitive to desiccation [8]. Paenibacterin caused intracellular potassium leakage, increased the cytoplasmic membrane permeability, decreased the biosynthesis of the osmoprotectant trehalose, and downregulated the expression of desiccation-related genes in desiccation-adapted S. enterica. Building on these findings, we hypothesized that food additives that are active against bacterial cytoplasmic membranes are likely to compromise the desiccation resistance in S. enterica. Such additives would revert the bacterium to its desiccation-sensitive status, and thus, enhance lethality by mild processing technologies. To test this hypothesis, the current study was initiated to (a) screen selected food additives for their ability to compromise the desiccation-resistance in S. enterica and (b) assess the ability of a membrane-active additive to inactivate $S$. enterica during milk spraydrying and freeze-drying. Desiccation-resistant Salmonella can survive in milk powder and pose food safety risk [9-13]. Therefore, milk powder is an appropriate model to evaluate methods to combat desiccation-resistant Salmonella.

\section{Material and Methods}

\subsection{Preparation of the Test Food Additives}

Ten food additives were screened for ability to cause potassium leakage from desiccation-adapted S. enterica. Carvacrol and thymol (Sigma Aldrich, St. Louis, MO, USA) were dissolved in 5\% dimethyl sulfoxide (DMSO; Sigma Aldrich). Eugenol, transcinnamaldehyde, vanillin, diacetyl, and catechin hydrate (Fisher Scientific, Fair Lawn, NJ, USA) were dissolved in $85 \%$ ethanol (Fisher Scientific). Benzoic, lactic, and citric acids (Fisher Scientific) were dissolved in sterile water. Five percent DMSO in saline $(\mathrm{NaCl} ; 0.85 \%$ $w t / v o l)$, ethanol $(85 \% \mathrm{vol} / \mathrm{vol})$, or deionized water was used as the additive-free control, depending on the solvent used in a given treatment.

\subsection{Bacterial Strains}

The S. enterica serovars used in this study are: (a) S. enterica serovar Tennessee E2007000304, a known desiccation-resistant serovar that was isolated originally from peanut butter [14], (b) S. enterica serovar Livingstone 1236H (formerly known as Eimsbuettel $1236 \mathrm{H}[8,15,16])$, a peanut butter isolate [17], and (c) S. enterica serovar Typhimurium ASD200. The latter is a genetically engineered mutant that was modified $(\Delta$ Salmonella pathogenicity island [SPI] I and $\Delta$ SP2) to an avirulent strain [18]. The strain ASD200 was used only for the spray-drying and freeze-drying experiments. Each serovar was grown in tryptic soy broth (TSB; BD, Sparks, MD, USA) at $37^{\circ} \mathrm{C}$ for $18 \mathrm{~h}$ before being subjected to desiccation adaptation.

\subsection{Preparation of Desiccation-Adapted S. enterica Serovars}

Desiccation-adapted Salmonella serovars were prepared as described in previous studies $[8,19]$ with modifications. Briefly, $S$. enterica serovars were grown overnight in TSB (BD) at $37^{\circ} \mathrm{C}$ to a cell density of $10^{9}$ colony forming unit (CFU)/mL as determined by plating on Tryptic Soy agar (TSA; BD). Cells of the obtained cultures were harvested by centrifugation at $4{ }^{\circ} \mathrm{C}$ and $10^{4} \times g$ for $5 \mathrm{~min}$ and resuspended in fresh TSB. Aliquots $(1 \mathrm{~mL})$ of the cell suspension were dispensed in plastic Petri dishes (90-mm diameter; VWR International, Chicago, IL, USA), with a final population of ca. $10^{9} \mathrm{CFU}$ per plate, and air-dried in a biosafety cabinet for $24 \mathrm{~h}$ at $22-25^{\circ} \mathrm{C}$ under circa $40 \%$ relative humidity to 
prepare desiccation-adapted dry cells. The dried cells were collected and resuspended in saline $(0.85 \% \mathrm{NaCl})$ to obtain desiccation-adapted cell suspension (DACS).

\subsection{Potassium Ion Release Assay}

Release of potassium ions was determined using a potassium-binding benzofuran isophthalate probe (PBFI; Invitrogen, Carlsbad, CA, USA) as described previously [8]. Briefly, DACS of Salmonella Tennessee and Livingstone were centrifuged and the cell pellets were resuspended in $5 \mathrm{mM}$ HEPES buffer (Sigma Aldrich) supplemented with $5 \mathrm{mM}$ glucose (Fisher Scientific). Aliquots $(90 \mu \mathrm{L})$ of the resuspended cells were added to wells of a black, nonbinding-surface, 96-well microplate (Corning, Tewksbury, MA, USA). The potassium probe was dispensed to each well at a final concentration of $2 \mu \mathrm{M}$ before the addition of $10 \mu \mathrm{L}$ of the food additives, which were prepared as described in a previous section. The food additives were applied at different concentrations (Figure 1) that ranged from sublethal to lethal levels that were reported in previous studies [20-26] except carvacrol and thymol, which were applied based on their MIC levels determined in the current study. Polymyxin at $10 \mathrm{ppm}$ was used as a positive control. Fluorescence, corresponding to potassium ions concentration, was measured using a microplate reader (Perkin-Elmer, Wellesley, MA, USA) at excitation and emission wavelength of 346 or $505 \mathrm{~nm}$, respectively. Fluorescence measurements were normalized by removing the background fluorescence noise.

\subsection{Determination of the Minimum Inhibitory Concentration (MIC)}

Two food additives, namely carvacrol and thymol, showed significant potassium leakage from Salmonella cells. Before these compounds were used for the heat treatment and food application studies, their MICs against S. enterica serovars were determined using the broth microdilution method [27]. Briefly, two-fold serial dilutions of carvacrol and thymol, at final concentrations of 800,400,200,100, and 50 ppm, were prepared before $50-\mu \mathrm{L}$ aliquots of these preparations were dispensed into the 96-well plates (Corning); this was followed by adding equal volume of Salmonella Tennessee or Livingstone culture suspension, which was adjusted to $\mathrm{OD}_{600}$ of 0.01 in TSB (BD Diagnostic). The MIC of each compound was determined as the lowest concentration, which completely inhibited the visible growth of S. enterica after $24 \mathrm{~h}$ of incubation at $37^{\circ} \mathrm{C}$.

\subsection{Treatment of Salmonella Serovars with Additive-Heat Combination}

Carvacrol and thymol were assessed for their capability to sensitize Salmonella serovars to mild heat treatment at $55^{\circ} \mathrm{C}$ for $15 \mathrm{~min}$. Briefly, $5 \mathrm{~mL}$ Salmonella Tennessee or Livingstone DACSs were treated with carvacrol, or thymol at their MIC (200 and $100 \mathrm{ppm}$, respectively), while untreated S. enterica DACS served as a heated control. Treated and untreated $S$. enterica cells were incubated in a pre-heated water bath at $55{ }^{\circ} \mathrm{C}$ for $15 \mathrm{~min}$, plus circa $2.5 \mathrm{~min}$ as the sample temperature come-up time. After the thermal treatment, all tubes were removed and held on ice before counts of Salmonella survivors were determined using standard plating on TSA (BD). 


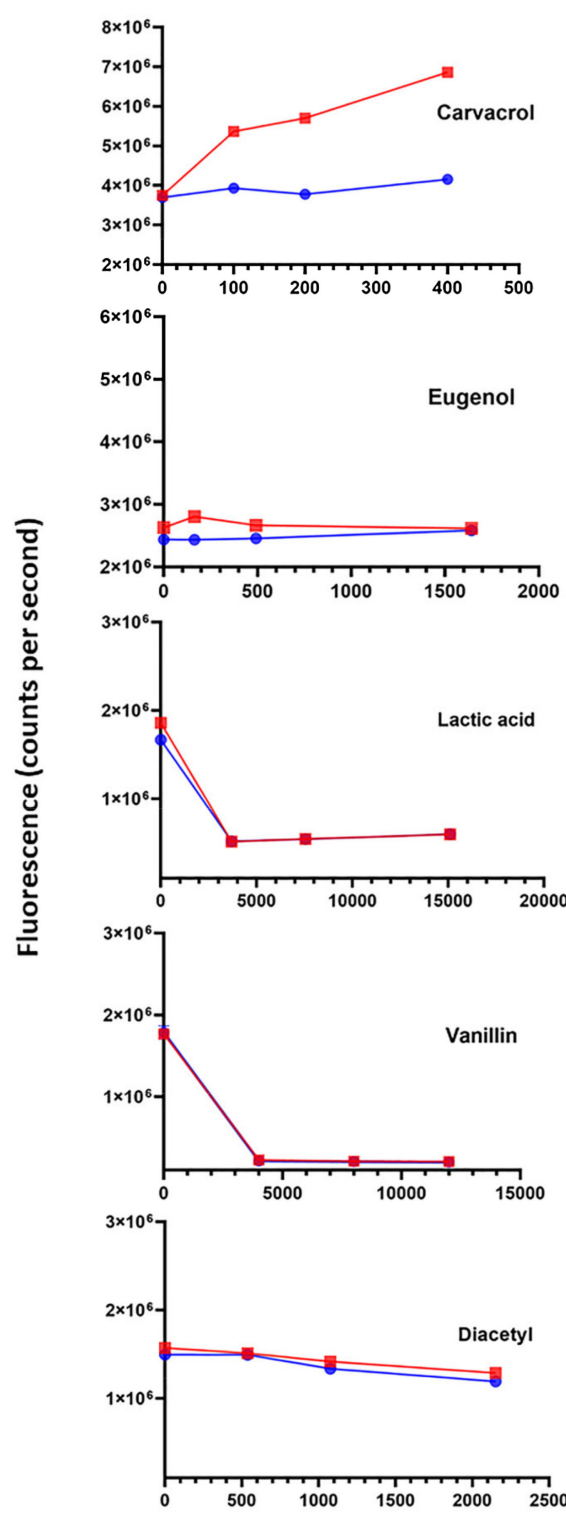

$\because$ S. Tennessee $\rightarrow$ S. Livingstone
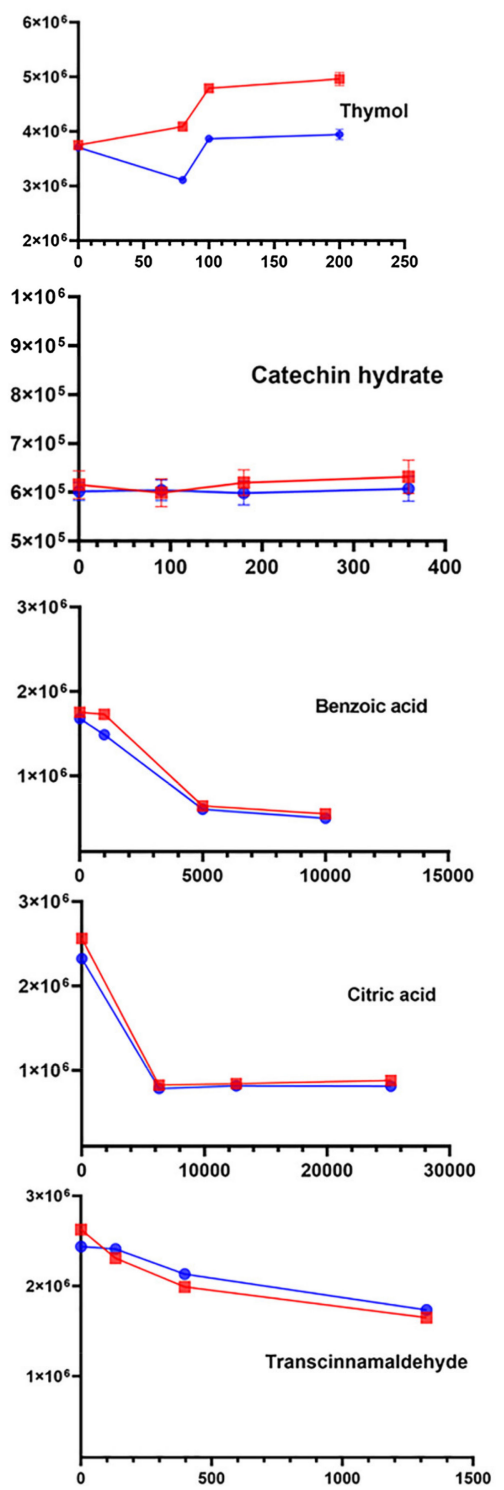

Concentration (ppm)

Figure 1. Changes in intracellular potassium ions from desiccation-adapted Salmonella enterica serovars in the presence of antimicrobial food additives. Values are the averages of three replicates.

\subsection{Inactivation of S. enterica in Milk during Spray-Drying}

Carvacrol was selected for applications in milk, as a model food, because of the superior ability of the additive to induce potassium leakage and its ability to sensitize $S$. enterica cells to heat. DACS of Salmonella Typhimurium ASD200 was added into $100 \mathrm{~mL}$ of liquid milk (Horizon; Organic low-fat milk, obtained for a local supermarket), and a final population of $\sim 10^{6} \mathrm{CFU} / \mathrm{mL}$ milk was achieved. Carvacrol at levels of 200 or $500 \mathrm{ppm}$ was added to the milk samples inoculated with S. enterica cells, while carvacrol-free inoculated milk samples served as untreated control. Treated and untreated milk samples were dried using a spray dryer (Yamato Scientific Co., Ltd., Tokyo, Japan) at $180^{\circ} \mathrm{C}$ and $50{ }^{\circ} \mathrm{C}$ for inlet and outlet temperatures, respectively, and a feed flow rate of $10 \mathrm{~mL}$ of liquid milk per min. Viable counts of Salmonella Typhimurium was determined by plating on the selective agar medium, xylose lysine tergitol-4 (XLT4; BD), before and immediately after spray-drying, and after 1-day storage of the spray-dried milk at $22-25^{\circ} \mathrm{C}$. S. enterica populations were 
determined as CFU/g milk solids. Total milk solids were determined by drying portions of the liquid or spray-dried milk samples on glass fiber pads for $3 \mathrm{~min}$, in a microwave oven, as described previously [28] and the percentage of total solids were calculated from the formula:

$$
\text { Total solids }(\%)=\left[\frac{\text { weight of dry milk sample }}{\text { weight of wet milk sample }}\right] \times 100
$$

\subsection{Inactivation of S. enterica in Milk during Freeze-Drying}

Liquid milk samples (Horizon) were inoculated with Salmonella Typhimurium ASD200 to achieve final cell density of $10^{7} \mathrm{CFU} / \mathrm{mL}$ before adding carvacrol at 200, 500, or $5000 \mathrm{ppm}$. The highest concentration tested (5000 ppm) was applied to enable significant reduction of Salmonella during freeze-drying. Untreated milk ( 0 ppm carvacrol) served as a control. All milk samples were frozen at $-80^{\circ} \mathrm{C}$ for $16-18 \mathrm{~h}$ before being dried for $48 \mathrm{~h}$ using a freeze dryer (Labconco, Kansas, MO, USA). Freeze-dried milk samples were stored for 2 days at $22-25^{\circ} \mathrm{C}$ to measure $S$. enterica survivors during storage. Salmonella viable counts were determined as CFU/g milk solids before, and immediately following freeze-drying, and on a daily basis during storage of the freeze-dried milk.

\subsection{Statistical Analysis}

All experiments were performed in triplicate and independently repeated two times, unless indicated otherwise. Bacterial populations were analyzed by analysis of variance (ANOVA) to determine significant differences between treatment groups or Student's t-test to compare pairs of treatment. The statistical analysis was completed using a statistical software (SPSS; IBM, New York, NY, USA) and a $p$ value of $<0.05$ was considered statistically significant.

\section{Results and Discussion}

\subsection{Screening Food Additives for the Ability to Disrupt Desiccation Resistance in Salmonella}

In a previous study, the membrane-active antimicrobial peptide, paenibacterin, disrupted the desiccation resistance mechanisms and sensitized S. enterica serovars to desiccation [8]. Therefore, we explored a similar effect in 10 food additives recognized to exert antimicrobial activity by acting on the bacterial cytoplasmic membrane [29]; these additive are also known to possess the "Generally Regarded As Safe" (GRAS) status. The concentration of additives used encompassed their MIC as reported previously or determined in the current study (Table 1).

The selected food additives were screened for ability to release $\mathrm{K}^{+}$ions from desiccationadapted S. enterica cells. Out of 10 antimicrobial food additives tested, carvacrol and thymol were the most capable of inducing potassium leakage in desiccation-adapted Salmonella Tennessee and Livingstone, as shown in Figure 1. Leakage of potassium ions, caused by carvacrol or thymol treatment, may indicate that Salmonella has lost one of its important protective factors required for adapting to desiccation $[8,19]$. If this is the case, treated Salmonella becomes sensitive to heat processing and drying stress. Moreover, leakage of intracellular potassium could make the bacterium unable to survive the dry environment during storage of contaminated low- $\mathrm{a}_{\mathrm{w}}$ food products. These hypotheses were tested in the following experiments. 
Table 1. The minimum inhibitory concentration (MIC) of the antimicrobial food additives against S. enterica.

\begin{tabular}{cccc}
\hline Category & Food Additive & $\begin{array}{c}\text { MIC } \\
(\mathbf{p p m})\end{array}$ & Source \\
\hline \multirow{2}{*}{ Plant-derived } & Carvacrol & 200 & Current study \\
Biomolecules & Thymol & 100 & Current study \\
& Trans-cinnamaldehyde & 3000 & {$[20]$} \\
& Eugenol & 512 & {$[21]$} \\
Weak organic & Vanillin & 8000 & {$[24]$} \\
\hline \multirow{2}{*}{ acids } & Citric acid & 12,624 & {$[23]$} \\
& Lactic acid & 7552 & {$[23]$} \\
\hline \multirow{2}{*}{ Microbially-derived } & Benzoic acid & $>6700$ a & {$[22]$} \\
& Diacetyl & 1076 & {$[25]$} \\
\hline
\end{tabular}

${ }^{a}$ Benzoic acid at more than $6700 \mathrm{ppm}$ was required to cause $50 \%$ decrease in S. enterica population after exposure

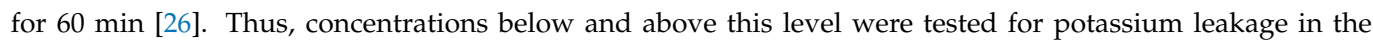
current study.

\subsection{Sensitizing Desiccation-Resistant Salmonella to Heat Treatment Using Selected Food Additives}

Carvacrol and thymol were investigated at their MIC (200 and 100 ppm, respectively) in combination with heat treatment at $55^{\circ} \mathrm{C}$ for 15 min against desiccation-adapted Salmonella Tennessee and Livingstone. Carvacrol, combined with heat treatment, caused reduction of the population of desiccation-adapted Salmonella Tennessee by more than $5.5 \log \mathrm{CFU} / \mathrm{mL}$, whereas the heat treatment alone caused $3.2 \pm 0.11 \log \mathrm{CFU} / \mathrm{mL}$ reduction (Figure 2A). For Salmonella Livingstone, carvacrol combined with heat reduced the pathogen by $4.1 \pm 0.21 \log \mathrm{CFU} / \mathrm{mL}$ compared to the heat treatment alone that caused $2.4 \pm 0.53 \log \mathrm{CFU} / \mathrm{mL}$ reduction (Figure $2 \mathrm{~B}$ ). On the other hand, thymol-heat treatment reduced Salmonella Tennessee and Livingstone populations by $4.3 \pm 0.22$ and $3.1 \pm 0.9 \log$ $\mathrm{CFU} / \mathrm{mL}$, respectively (Figure $2 \mathrm{~A}, \mathrm{~B})$, compared to the heat treatment alone (3.2 \pm 0.11 and $2.4 \pm 0.53 \log \mathrm{CFU} / \mathrm{mL}$ reduction for Tennessee and Livingstone, respectively). These findings indicate that combining food additives with heat is more lethal $(p<0.05)$ than applying heat individually and that serovar Tennessee is more sensitive than Livingstone to this treatment combination. The synergistic effect of carvacrol or thymol with heat could be attributed to the ability of the antimicrobial compounds to damage the cytoplasmic membrane of Salmonella cells and further affect the equilibrium of the inorganic ions and induce cell injury [30]. The injury of Salmonella by these additives made the bacterium sensitive to heat stress which can damage critical cellular macromolecules, particularly proteins [31]. It is likely that leakage of $\mathrm{K}^{+}$and other osmoprotectans increased intracellular water availability, which, in turn, increases the sensitivity of cellular proteins to heat. 
Salmonella Tennessee

A

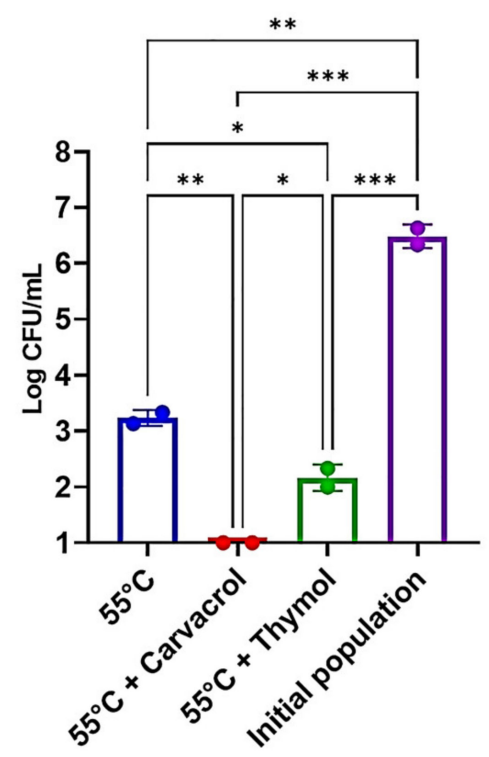

Salmonella Livingstone

B

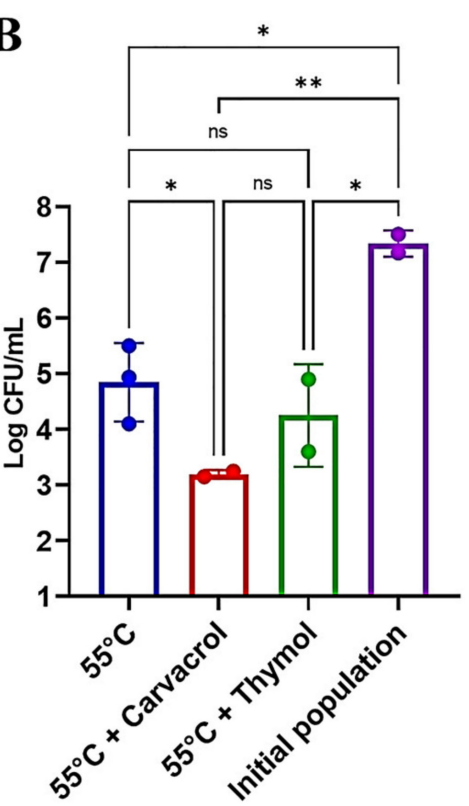

Figure 2. Changes in populations of desiccation-adapted Salmonella Tennessee (A) and Livingstone (B) in response to heat treatment and pretreatment with carvacrol and thymol. Values are averages of three replicates \pm standard deviation. Asterisks denote significant differences between averages $\left({ }^{*} p<0.05,{ }^{* *} p<0.01,{ }^{* * *} p<0.001\right)$, "ns" = not significantly different.

\subsection{Inactivation of S. enterica in Milk during Spray-Drying}

Carvacrol was investigated for the ability to sensitize Salmonella Typhimurium ASD200 to spray-drying. The strain ASD200 has been genetically modified through deletion of SPI-1 and SPI-2, and thus, it is suitable for safe use in drying experiments. Carvacrol at 200 or 500 ppm significantly $(p<0.05)$ decreased the viability of the desiccation-adapted strain ASD200 in response to spray-drying, compared to the carvacrol-free control. This effect was observed after 1-day storage of the spray-dried milk at room temperature (Table 2). In contrast, when Salmonella populations were determined in the milk powder immediately following spray-drying, no significant difference $(p>0.05)$ was detected between carvacroltreated or untreated milk. Overall, the results suggest that carvacrol-treated Salmonella cells did not implement desiccation resistance in the spray-dried milk during storage, and thus, became dehydration-sensitive. This explanation is supported by a previous finding that pretreatment of desiccation-adapted Salmonella with the membrane-active paenibacterin sensitized the cells to subsequent $24 \mathrm{~h}$ of desiccation at room temperature [8]. 
Table 2. Inactivation of Salmonella Typhimurium ASD200 during spray-drying of milk with or without carvacrol.

\begin{tabular}{cccc}
\hline Treatment Time & Moisture Content (\%) & $\begin{array}{c}\text { Salmonella Population } \\
\text { (Log CFU/g Milk Solids) }\end{array}$ & $\begin{array}{c}\text { Log CFU/g } \\
\text { Reduction * }\end{array}$ \\
\hline Time 0 & Control (0 ppm carvacrol) & \\
\hline After drying & 85.86 & $5.6 \pm 0.0 .05$ & $0.0 \pm 0.00$ \\
\hline 1-day storage & 4.67 & $5.3 \pm 0.21$ & $0.3 \pm 0.26$ \\
\hline Time 0 & 0.25 & $5.0 \pm 0.07$ & $\mathbf{0 . 6} \pm \mathbf{0 . 0 2 a}{ }^{\#}$ \\
\hline After drying & \multicolumn{2}{c}{ Carvacrol (200 $\mathbf{~ p p m ) ~}$} & $0.0 \pm 0.00$ \\
\hline 1-day storage & 85.86 & $6.1 \pm 0.51$ & $0.2 \pm 0.34$ \\
\hline & 4.67 & $5.9 \pm 0.17$ & $\mathbf{0 . 9} \pm \mathbf{0 . 0 2} \mathbf{b}$ \\
\hline Time 0 & 0.25 & $5.2 \pm 0.53$ & $0.0 \pm 0.00$ \\
\hline After drying & 85.86 & Carvacrol (500 $\mathbf{~ p p m ) ~}$ & $0.5 \pm 0.00$ \\
\hline 1-day storage & 4.67 & $6.6 \pm 0.02$ & $\mathbf{1 . 3} \pm \mathbf{0 . 1 0 c}$ \\
\hline
\end{tabular}

* The reduction in Salmonella ASD200 populations was calculated in reference to the initial population before spray-drying. ${ }^{* *}$ Refers to the initial population of Salmonella ASD200 before starting the spray-drying process. Salmonella ASD200 population reductions, highlighted in bold, indicate the highest lethal effects of carvacrol treatments ${ }^{\#}$ Data followed by different letters indicate significant difference $(p<0.05)$.

\subsection{Inactivation of S. enterica in Milk during Freeze-Drying}

Freeze-drying is a dehydration process that is used for preservation of many foods such as fruits, seafood, coffee, and others [32]. In the current study, carvacrol at different concentrations $(200,500$, and 5000 ppm) was added into liquid milk to sensitize Salmonella Typhimurium ASD200 to the dehydration stress mediated by freeze-drying. Compared to the carvacrol-free freeze-dried milk, samples with carvacrol at $5000 \mathrm{ppm}$ decreased Salmonella Typhimurium population below the detection limit of the enumeration method, which was $3 \log \mathrm{CFU} / \mathrm{g}$ milk (Figure 3). This population reduction was observed immediately following freeze-drying and during the 2-day storage of the dried milk at $22-25^{\circ} \mathrm{C}$. In contrast, treatment with carvacrol at 200 or 500 ppm did not significantly $(p>0.05)$ reduce Salmonella levels in the freeze-dried product, compared to the carvacrol-free control (Figure 3).

To determine whether the anti-Salmonella activity observed by the combination of carvacrol (at $5000 \mathrm{ppm}$ ) and freeze-drying was a synergistic effect between the two lethal factors, a treatment using $5000 \mathrm{ppm}$ carvacrol without freeze-drying was conducted. As shown in Table 3, it was obvious that Salmonella Typhimurium survivors were lower following treatment with carvacrol and freeze-drying combination than they were when carvacrol alone was applied. Results from the drying experiments imply that higher concentration of carvacrol ( $\geq 10$-fold) was required to decrease Salmonella populations during freeze-drying, compared to that used in the spray-drying. These findings are plausible considering that spray-drying includes heat; therefore, the bacterium suffered thermal and dehydration stresses, whereas freeze-drying caused dehydration stress only. 


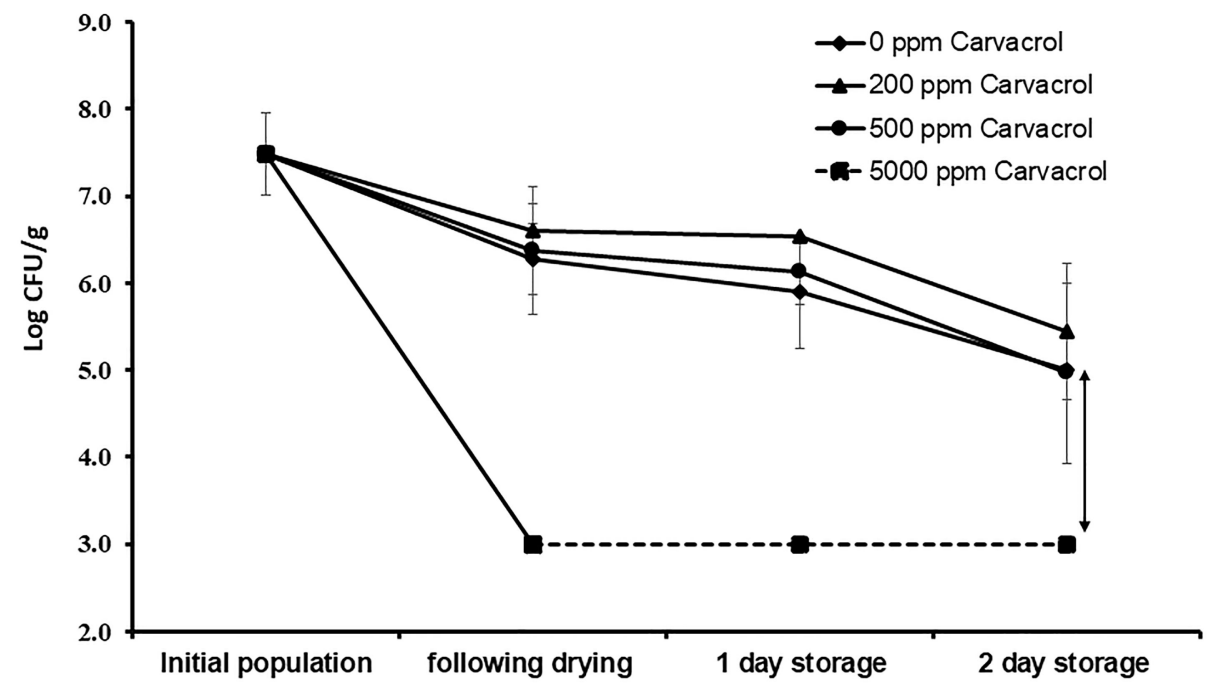

Figure 3. Changes in Salmonella Typhimurium populations (log CFU/g milk solids) in the freezedried milk processed without or with carvacrol when applied at different concentrations. Values are the averages of three replicates \pm standard deviation. The dashed line indicates that Salmonella populations were below the enumeration method's detection limit (i.e., $3 \log \mathrm{CFU} / \mathrm{g}$ ).

Table 3. Changes of Salmonella Typhimurium populations in carvacrol-treated milk followed with or without freeze-drying.

\begin{tabular}{ccccc}
\hline \multirow{2}{*}{ Treatment } & \multicolumn{3}{c}{ Log CFU/g Total Solids of Milk } \\
\cline { 2 - 5 } & $\begin{array}{c}\text { Initial } \\
\text { Population }\end{array}$ & Day-0 & 1-Day Storage & 2-Day Storage \\
\hline $\begin{array}{c}\text { Carvacrol (5000 ppm) } \\
+ \text { Freeze-drying }\end{array}$ & $7.5 \pm 0.5$ & $<3^{\text {a }}$ & $<3^{\text {a }}$ & $<3^{\text {a }}$ \\
\hline Carvacrol (5000 ppm) & $7.5 \pm 0.3$ & $5.4 \pm 0.02$ & $3.9 \pm 0.6$ & $4.9 \pm 0.4$ \\
\hline
\end{tabular}

Based on these findings, the inclusion of the membrane-active food additive, carvacrol, during drying is advantageous since the compound manipulates Salmonella's physiology in a manner that disrupts the desiccation resistance in pathogen cells. The additive pretreatment made it easy to inactivate Salmonella cells by mild processing such as drying, a process which was also recognized to cause cell death of S. enterica by increasing cytoplasmic membrane permeabilization [33]. An additional advantage is that the application of the antimicrobial food additive carvacrol at $5000 \mathrm{ppm}$ with freeze-drying caused more than $4.5 \log \mathrm{CFU} / \mathrm{g}$ reduction in S. enterica. Comparably, a similar reduction in Salmonella populations was achieved in non-fat dry milk by applying high temperature $\left(115^{\circ} \mathrm{C}\right.$ for $\left.1 \mathrm{~h}\right)$, but this heat treatment impaired the color and gave the powder a burned appearance [34]. Therefore, targeting the cytoplasmic membrane by the membrane-active carvacrol prior to drying is a valuable approach considering it helps overcoming Salmonella desiccation resistance and sensitizes the pathogen to the drying processing. The process is also likely to have minimal impact on the milk sensory characteristics, albeit this effect was not tested in the current study.

\section{Conclusions}

The natural antimicrobials, carvacrol and thymol, decreased desiccation resistance in S. enterica via induction of intracellular potassium leakage, and this sensitized the pathogen to heat stress. For translating these findings in a food model, the presence of carvacrol during dehydrating liquid milk using freeze- or spray-drying increased the process lethality. Carvacrol is a commercially available GRAS additive, and its use can protect against $S$. enterica contamination and improve the safety of low $-a_{w}$ foods. Future research is needed 
to determine the effectiveness of carvacrol against desiccation-resistant S. enterica in various foods having limited water availability. These are not limited to dehydrated products; it also included frozen foods. Additionally, usage of carvacrol should be optimized to minimize any undesirable sensory changes in treated products.

Author Contributions: A.G.A.: research conceptualization and design, experimental analysis, and manuscript writing. A.E.Y.: research design, manuscript writing and reviewing, and project management. All authors have read and agreed to the published version of the manuscript.

Funding: Financial support was provided by the Center for Advanced Processing and Packaging Studies, a National Science Foundation Industry-University Cooperative Research Center.

Institutional Review Board Statement: Not applicable

Informed Consent Statement: Not applicable.

Data Availability Statement: Not applicable.

Conflicts of Interest: The authors declare no conflict of interest.

\section{References}

1. Beuchat, L.R.; Komitopoulou, E.; Beckers, H.; Betts, R.P.; Bourdichon, F.; Fanning, S.; Joosten, H.M.; Ter Kuile, B.H. Low-water activity foods: Increased concern as vehicles of foodborne pathogens. J. Food Prot. 2013, 76, 150-172. [CrossRef]

2. Russo, E.T.; Biggerstaff, G.; Hoekstra, R.M.; Meyer, S.; Patel, N.; Miller, B.; Quick, R. A recurrent, multistate outbreak of Salmonella serotype Agona infections associated with dry, unsweetened cereal consumption, United States, 2008. J. Food Prot. 2013, 76, 227-230. [CrossRef] [PubMed]

3. Food and Drug Administration (FDA). FDA Investigated Multistate Outbreak of Salmonella Infections Linked to Raw Nut Butter Products I FDA. 2014. Available online: https: / / www.fda.gov/food/outbreaks-foodborne-illness/fda-investigated-multistateoutbreak-salmonella-infections-linked-raw-nut-butter-products (accessed on 15 December 2020).

4. FDA. Recalls, Market Withdrawals \& Safety Alerts. 2018. Available online: https://www.fda.gov/safety/archive-recalls-marketwithdrawals-safety-alerts / 2018-recalls-market-withdrawals-safety-alerts (accessed on 15 December 2020).

5. Food and Agricultural Organization (FAO); World Health Organization (WHO). Ranking of Low Moisture Foods in Support of Microbiological Risk Management. Report of an FAO/WHO Consultation Process. 2014. Available online: http://www. fao.org/tempref/codex/Meetings/CCFH/ccfh46/FAO_WHO\%20Presentation\%20on\%20LMF\%20ranking.pdf (accessed on 15 December 2020).

6. Finn, S.; Condell, O.; McClure, P.; Amézquita, A.; Fanning, S. Mechanisms of survival, responses, and sources of Salmonella in low-moisture environments. Front. Microbiol. 2013, 4, 1-15. [CrossRef] [PubMed]

7. Ma, L.; Zhang, G.; Gerner-Smidt, P.; Mantripragada, V.; Ezeoke, I.; Doyle, M.P. Thermal inactivation of Salmonella in Peanut Butter. J. Food Prot. 2009, 72, 1596-1601. [CrossRef]

8. Abdelhamid, A.G.; Yousef, A.E. The microbial lipopeptide paenibacterin disrupts desiccation resistance in Salmonella enterica serovars Tennessee and Eimsbuettel. Appl. Environ. Microbiol. 2019, 85. [CrossRef] [PubMed]

9. Lian, F.; Zhao, W.; Yang, R.; Tang, Y.; Katiyo, W. Survival of Salmonella enterica in skim milk powder with different water activity and water mobility. Food Control 2015, 47, 1-6. [CrossRef]

10. Angulo, F.J.; Cahill, S.M.; Wachsmuth, I.K.; Costarrica, M.D.L.; Embarek, P.K.B. Powdered infant formula as a source of Salmonella infection in infants. Clin. Infect. Dis. 2008, 46, 268-273. [CrossRef]

11. Rowe, B.; Hutchinson, D.N.; Gilbert, R.J.; Hales, B.H.; Begg, N.T.; Dawkins, H.C.; Jacob, M.; Rae, F.A.; Jepson, M. Salmonella Ealing infections associated with consumption of infant dried milk. Lancet 1987, 330, 900-903. [CrossRef]

12. Jourdan-da Silva, N.; Fabre, L.; Robinson, E.; Fournet, N.; Nisavanh, A.; Bruyand, M.; Mailles, A.; Serre, E.; Ravel, M.; Guibert, V.; et al. Ongoing nationwide outbreak of Salmonella Agona associated with internationally distributed infant milk products, France, December 2017. Eurosurveillance 2018, 23. [CrossRef]

13. Louie, K.K.; Paccagnella, A.M.; Osei, W.D.; Lior, H.; Francis, B.J.; Osterholm, M.T. Salmonella serotype Tennessee in powdered milk products and infant formula-Canada and United States, 1993. JAMA J. Am. Med. Assoc. 1993, 270, 432. [CrossRef]

14. Enache, E.; Kataoka, A.; Black, D.G.; Napier, C.D.; Podolak, R.; Hayman, M.M. Development of a dry inoculation method for thermal challenge studies in low-moisture foods by using Talc as a carrier for Salmonella and a surrogate (Enterococcus faecium). J. Food Prot. 2015, 78, 1106-1112. [CrossRef]

15. Abdelhamid, A.G.; Yousef, A.E. Collateral adaptive responses induced by desiccation stress in Salmonella enterica. LWT 2020, 133, 110089. [CrossRef]

16. Abdelhamid, A.G.; Xu, Y.; Yousef, A.E. Draft genome sequence of Salmonella enterica subsp. enterica serovar Livingstone 1236H, a desiccation-resistant strain that poses a salmonellosis hazard in low-moisture foods. Microbiol. Resour. Announc. 2021, 10, e01197-20. [CrossRef] 
17. Peña-Meléndez, M.; Perry, J.J.; Yousef, A.E. Changes in thermal resistance of three Salmonella serovars in response to osmotic shock and adaptation at water activities reduced by different humectants. J. Food Prot. 2014, 77, 914-918. [CrossRef] [PubMed]

18. Sabag-Daigle, A.; Blunk, H.M.; Gonzalez, J.F.; Steidley, B.L.; Boyaka, P.N.; Ahmer, B.M.M. Use of attenuated but metabolically competent Salmonella as a probiotic to prevent or treat Salmonella infection. Infect. Immun. 2016, 84, 2131-2140. [CrossRef]

19. Gruzdev, N.; McClelland, M.; Porwollik, S.; Ofaim, S.; Pinto, R.; Saldinger-Sela, S. Global transcriptional analysis of dehydrated Salmonella enterica serovar Typhimurium. Appl. Environ. Microbiol. 2012, 78, 7866-7875. [CrossRef]

20. Helander, I.M.; Alakomi, H.L.; Latva-Kala, K.; Mattila-Sandholm, T.; Pol, I.; Smid, E.J.; Gorris, L.G.M.; von Wright, A. Characterization of the action of selected essential oil components on Gram-negative bacteria. J. Agric. Food Chem. 1998, 46, 3590-3595. [CrossRef]

21. Miladi, H.; Zmantar, T.; Kouidhi, B.; Chaabouni, Y.; Mahdouani, K.; Bakhrouf, A.; Chaieb, K. Use of carvacrol, thymol, and eugenol for biofilm eradication and resistance modifying susceptibility of Salmonella enterica serovar Typhimurium strains to nalidixic acid. Microb. Pathog. 2017, 104, 56-63. [CrossRef]

22. Olasupo, N.A.; Fitzgerald, D.J.; Gasson, M.J.; Narbad, A. Activity of natural antimicrobial compounds against Escherichia coli and Salmonella enterica serovar Typhimurium. Lett. Appl. Microbiol. 2003, 37, 448-451. [CrossRef]

23. Humayoun, S.B.; Hiott, L.M.; Gupta, S.K.; Barrett, J.B.; Woodley, T.A.; Johnston, J.J.; Jackson, C.R.; Frye, J.G. An assay for determining the susceptibility of Salmonella isolates to commercial and household biocides. PLoS ONE 2018, 13, e0209072. [CrossRef] [PubMed]

24. Obaidat, M.M.; Alu'Datt, M.H.; Bani Salman, A.E.; Obaidat, H.M.; Al-Zyoud, A.A.; Al-Saleh, O.K.; Abu al'anaz, B. Inactivation of nondesiccated and desiccated Cronobacter Sakazakii and Salmonella spp. at low and high inocula levels in reconstituted infant milk formula by vanillin. Food Control 2015, 50, 850-857. [CrossRef]

25. Skroza, D.; Šimat, V.; Smole Možina, S.; Katalinić, V.; Boban, N.; Generalić Mekinić, I. Interactions of resveratrol with other phenolics and activity against food-borne pathogens. Food Sci. Nutr. 2019, 7, 2312-2318. [CrossRef] [PubMed]

26. Friedman, M.; Henika, P.R.; Mandrell, R.E. Antibacterial activities of phenolic benzaldehydes and benzoic acids against Campylobacter jejuni, Escherichia coli, Listeria monocytogenes, and Salmonella enterica. J. Food Prot. 2003, 66, 1811-1821. [CrossRef]

27. Wikler, M.A.; Cockerill, F.R.; Craig, W.A.; Dudley, M.N.; Eliopoulos, G.M.; Hecht, D.W.; Hindler, J.F.; Low, D.E.; Sheehan, D.J.; Tenover, F.C.; et al. Methods for dilution antimicrobial susceptibility tests for bacteria that grow aerobically: Approved Standard Seventh Edition (M7-A7). In CLSI Guidelines; Clinical \& Laboratory Standards Institute: Annapolis Junction, MD, USA, 2006; ISBN 156238600X.

28. Reh, C.T.; Gerber, A. Total solids determination in dairy products by microwave oven technique. Food Chem. 2003, 82, 125-131. [CrossRef]

29. Nair, M.S.; Upadhyaya, I.; Amalaradjou, M.A.R.; Venkitanarayanan, K. Antimicrobial food additives and disinfectants. In Foodborne Pathogens and Antibiotic Resistance; John Wiley \& Sons, Inc.: Hoboken, NJ, USA, 2017; pp. $275-301$.

30. Lambert, R.J.W.; Skandamis, P.N.; Coote, P.J.; Nychas, G.J.E. A study of the minimum inhibitory concentration and mode of action of oregano essential oil, thymol and carvacrol. J. Appl. Microbiol. 2001, 91, 453-462. [CrossRef] [PubMed]

31. Guevara, L.; Antolinos, V.; Palop, A.; Periago, P.M. Impact of moderate heat, carvacrol, and thymol treatments on the viability, injury, and stress response of Listeria monocytogenes. Biomed. Res. Int. 2015, 1-10. [CrossRef]

32. Waghmare, R.B.; Perumal, A.B.; Moses, J.A.; Anandharamakrishnan, C. Recent developments in freeze drying of foods. In Innovative Food Processing Technologies; Elsevier: Amsterdam, The Netherlands, 2021; pp. 82-99.

33. Lang, E.; Guyot, S.; Peltier, C.; Alvarez-Martin, P.; Perrier-Cornet, J.M.; Gervais, P. Cellular injuries in Cronobacter sakazakii CIP 103183T and Salmonella enterica exposed to drying and subsequent heat treatment in milk powder. Front. Microbiol. $2018,9,475$. [CrossRef] [PubMed]

34. McDonough, F.E.; Hargrove, R.E. Heat resistance of Salmonella in dried milk. J. Dairy Sci. 1968, 51, 1587-1591. [CrossRef] 